\title{
Suça Sürüklenen Çocuklarda Akıllı Telefon Bağımlılığı, Siber Zorbalık ve Siber Mağduriyetin Değerlendirilmesi
}

\section{Evaluation of Smartphone Addiction, Cyberbullying and Cyber Victimization in Children Dragged to Crime}

\author{
Özge Gizli ÇOBAN, Arif ÖNDER
}

Akdeniz Üniversitesi Tıp Fakültesi, Çocuk ve Ergen Ruh Sağlığı Anabilim Dalı, Antalya, Türkiye

Yazışma Adresi

Correspondence Address

\section{Özge GIZLLI ÇOBAN}

Akdeniz Üniversitesi Tıp Fakültesi, Çocuk ve Ergen Ruh

Sağlığı Anabilim Dalı,

Antalya, Türkiye

ozgegizli87@gmail.com

Geliş tarihi / Received : Oca 08, 2021 Kabul tarihi / Accepted : Mar 04, 2021

Elektronik yayın tarihi : Eyl 01, 2021 Online published

Bu makalede yapılacak atıf:

Cite this article as:

Gizli Çoban Ö, Önder A.

Suça Sürüklenen Çocuklarda Akıllı

Telefon Bağımlılı̆̆,

Siber Zorbalık ve Siber

Mağduriyetin Değerlendirilmesi

Akd Tip D / 2021; 7(3):430-435

Özge Gizli ÇOBAN,

ORCID ID: 0000-0003-4533-105X Arif ÖNDER

ORCID ID: 0000-0003-0571-9295
Öz:

Amaç:

Bu çalışmada polikliniğimize adli vaka olarak gelen suça sürüklenen çocuklarda, akıllı telefon bağımlılığı, sosyal medya bağımlılığı, siber zorbalık ve siber mağduriyetin değerlendirilmesi amaçlanmıştır.

\section{Yöntem:}

Bu çalışmaya, polikliniğimize Eylül 2019-Temmuz 2020 tarihleri arasında adli makamlarca yönlendirilen 12-15 yaş arası suça sürüklenen çocuklar alınmıştır. Olgulara Akıllı Telefon Bağıml1lığı Ölçeği, Olweus Akran Zorbalığı Ölçeği, Sosyal Medya Bağımlılığı Ölçeği Kısa Formu, Siber Zorbalık ve İnternet Saldırganlığını Tarama Ölçeği(SZISTÖ) verilmiş̧tir.

\section{Bulgular:}

Çalışmaya alınan 45 olgunun 35'i $(\% 77,8)$ erkek, 10 ’u $(\% 22,2)$ kızdır. İşlendiği iddia olunan en sık suç \%28,9 ile "kavga/yaralama"dır. Akıllı telefon bağımlılığı ölçeğinden elde edilen skorlar "düşük/orta/yüksek" olarak kategorize edildiğinde, \%62,2'sinin düşük, \%24,4'ü orta, \%4,4'ünün yüksek kategorisinde olduğu saptanmıştır. Olguların sadece 2 'sinde $(\% 4,4)$ sosyal medya bağımlılığı saptanmıştır. Olgular akran zorbalığı açısından değerlendirildiğinde \%15,6'sının mağdur, \%8,6's1 zorba, \%73,3'ünün ne mağdur ne de zorba olduğu saptanmıştır. SZISTÖ'ne göre olguların \%15,6'sının siber mağduriyet yaşadığı, \%8,9'unun siber zorbalık yapmış olduğu saptanmıştır.

\section{Sonuç:}

Suça sürüklenen çocuklardaki akıllı telefon bağımlılığı, sosyal medya bağımlılığı ve bunların neden olabileceği siber zorbalık ve siber mağduriyet arasındaki ilişkileri belirlemek için büyük örneklemlere ihtiyaç vardır. Hem ailelere hem de öğretmen ve öğrencilere yönelik telefon ve bilgisayar gibi teknolojik araçların bilinçli olarak kullanılması, güvenli internet kullanımı, siber zorbalık ve siber suç farkındalığını sağlayacak eğitimler verilmelidir.

Anahtar kelimeler: Suça sürüklenen çocuk; Akıllı telefon bağımlılı̆̆ı; Zorba; Mağdur; Siber zorbalık

\footnotetext{
Abstract:

Objective: In the present study, it was aimed to evaluate smartphone addiction, social media addiction, cyberbullying and cybervictimization in children dragged into crime who applied our outpatient clinic as forensic case.

Method: Subjects between the ages of 12-15, who were referred to our outpatient clinic by the judicial authorities between September 2019-July 2020, were included in this study. The subjects
} 
were given the Smartphone Addiction Scale, the Olweus Peer Bullying Scale, the Short Form of the Social Media Addiction Scale, the Cyberbullying and Internet Aggression Screening Scale.

\section{Results:}

Of the 45 cases included in the study, $35(77,8 \%)$ were male and $10(22,2 \%)$ were female. The most commonly commited crime was "fight / injury" with 28,9\%. When the scores obtained from the Smartphone Addiction Scale were categorized as "low / medium / high", 62,2\% were in the low, 24,4\% in the medium and $4,4 \%$ in the high category. Social media addiction was found in only $2(4,4 \%)$ of the cases. When the cases are evaluated in terms of peer bullying, it was found that $15,6 \%$ were victims, $8,6 \%$ were bullies, and $73,3 \%$ were neither victim nor bully. According to the CBOASI, $15,6 \%$ of the cases experienced cyber victimization and $8,9 \%$ had cyberbullying.

\section{Conclusion:}

Large samples are needed to determine the relationships between smartphone addiction, social media addiction and cyberbullying and cybervictimization among children dragged into crime. Education should be given to both parents and teachers and students to ensure conscious use of technological tools such as phones and computers, internet security, cyberbullying and cybercrime awareness.

Keywords: Juvenile delinquency; Smartphone addiction; Bully; Victim; Cyberbullying

\section{Giriş}

Kanunlarda suç olarak tanımlanan bir fiili işlediği iddiası ile hakkında soruşturma ya da kovuşturma yürütülen veya işlediği iddia olunan fiilden dolayı hakkında güvenlik tedbiri konulmasına karar verilen çocuklar, Çocuk Koruma Kanununa göre "Suça Sürüklenen Çocuk" olarak tanımlamaktadır. Bu yaklaşımla suça sürüklenen çocuğun cezaland1rılması yerine korunması amaçlanmış olup, çocuğun suçun faili olmayıp suça sürüklendiği kabul edilmiştir (1).

Adli psikiyatrik değerlendirme, çocuk ve gençlerde mahkeme karar süreci için rapor düzenlenerek bilgi sağlanmasına ek olarak, eşlik edebilecek psikiyatrik hastalıkların değerlendirilmesi ve çocuğun korunabilmesi için de ayrıca önemlidir. Çocuğun suçun hukuki anlam ve sonuçlarını algılayıp algılamadığ1 ve davranışlarını yönlendirme yeteneğinin gelişip gelişmediği, suça sürüklenen çocuklara yönelik olarak adli kurumlarca en sik sorulan sorudur (2). Bu değerlendirmede çocuğun içinde doğup büyüdüğü çevre koşulları ile birlikte zihinsel, fiziksel, ruhsal, sosyal ve ahlaki ve sosyal gelişimi değerlendirilir (3).

Günümüz toplumunda insanlar başta akıllı telefonlar olmak üzere, çeşitli elektronik iletişim araçlarıyla, sosyal medya aracılığıyla diğer insanlarla iletişime geçebilmektedir. Fakat birçok avantajı olan sosyal medya, bazı tehlikeleri de beraberinde getirmektedir (4). Özellikle, ergenler hala sosyal olarak gelişme sürecinde oldukları için akıllı telefon bağım- lılığına karşı savunmasızdırlar (5). Sosyal ağların kriminal kullanımı, sosyal ağ kullanımının yaygınlaşması ile birlikte sosyal ağlara ayrılan zamanın artmasıyla önemli bir sorun haline gelmiştir. Sosyal ağ aracılığıyla suçla karşı karşıya kalınması, yeni suç kavramlarını da beraberinde getirmiştir (6). Yapılan çalışmalar, ergen akıllı telefon bağımlılığının, siber cinsel içeriğe erişme olasılığı ve siber sözlü şiddete katılma sıklığı üzerinde önemli ölçüde etkiye sahip olduğunu göstermiştir (5). Bir grup üniversitesi öğrencisinde yapılan güncel bir çalışmada, akıllı telefon bağımlılığının siber zorbalığı öngörebileceği sonucuna varılmıştır (7).

Bizim çalışmamızda polikliniğimize adli vaka olarak gelen suça sürüklenen çocuklarda, akıllı telefon bağımlılığı, sosyal medya bağımlılığı, siber zorbalık ve siber mağduriyetin değerlendirilmesi amaçlanmıştır. Bildiğimiz kadarıyla bu çalışma bu alanda yapılan ilk çalışmadır.

\section{Gereç ve Yöntem}

Bu çalışmaya, Çocuk ve Ergen Psikiyatrisi Polikliniğine Eylül 2019- Temmuz 2020 tarihleri arasında adli makamlarca suç işlediği iddiası ile adli rapor düzenlenmesi için yönlendirilen 12-15 yaş arası suça sürüklenen 45 çocuk alınmıştır. Suç işleme iddiası dışındaki diğer nedenlerle rapor düzenlenmesi için yönlendirilen adli olgular ve eşlik eden zihinsel geriliği olan olgular çalışmaya dahil edilmemiştir. Çalışma Helsinki Deklarasyonu'na uygun olarak yürütülmüş olup Akdeniz Üniversitesi Klinik Araştırmalar Etik Kurulu'ndan onay alınmıştır (Karar no:788/ tarih: 28/08/2019). Tüm katılımcılara çalışma ile ilgili bilgi verilmiştir ve çalışmaya katılmaya gönüllü olanlar, yazılı onam formları alındıktan sonra verilen ölçekleri doldurmuşlardır. Çalışmaya okuma-yazmayı bilen ve zihinsel gelişimi normal düzeyde olan çocuk ve ergenler alınmıştır.

Sosyodemografik veri formu: Araştırmacılar tarafından hazırlanmıştır. Yaş, cinsiyet, anne ve babanın ayrı olup olmadı̆̆ı, annenin eğitim düzeyi, babanın eğitim düzeyi, sosyoekonomik düzey, sigara ve madde kullanımı, evde televizyon/bilgisayar/tablet/kendine ait akıllı telefon/oyun konsolu olup olmadığı, varsa bunlarla günlük ne kadar süre geçirdiği, oynadığı oyunlarda çoklu online veya tek kişilik oyunlardan hangisi tercih ettiği görüşmeci tarafından sorularak değerlendirildi. İşlediği iddia olunan suç ve daha önce adli vaka olarak gelip gelmediği müzekkerede yazılan bilgilerden elde edildi.

Akıllı Telefon Bağımlılı̆̆ı Ölçeği: Kwon ve arkadaşları (8) tarafından geliştirilen ölçeğin lise öğrencilerinde Türkçe standardizasyonunu Şata ve arkadaşları yapmıştır (9). Ölçek, bireyin akıllı telefona bağımlılığını ölçmekte olup, 6'lı Likert türü derecelemeyi kullanan 33 maddeden oluşmaktadır. Bu ölçekten elde edilen puan aralığı 33 ila 198 puan arasındadır. Yüksek puanlar ciddi telefon bağımlılığına işaret etmektedir. Bu çalışmada akıllı telefon bağımlılığı skorları yorumlanırken, 33-88 arası düşük, 89-143 arası orta ve 144-198 arası yüksek olarak yorumlandı (10). 


\section{Olweus Akran Zorbalığı Ölçeği:}

Dan Olweus tarafindan 1983 yılında geliştirilmiş ve 1996 yılında yeniden düzenlenmiştir (11). Ölçeğin Türkçe geçerlilik ve güvenilirlik çalışması 2018 yılında Sipahi ve Karababa tarafından yapılmıştır (12). Ölçek 39 maddeden oluşmaktadır. Anketin başında, akran zorbalığının ayrıntılı bir açıklaması vardır. Ölçeğin zorbalık ve mağduriyet olmak üzere iki alt boyutu vardır. Genellikle zorba ve mağdur maddelerine verilen yanıtlar gençleri katılmayan, mağdur, zorba ve zorba mağdur grupları olarak sınıflandırmak için kullanılır. Zorbalık veya mağduriyetin ayda 2-3 kez yinelenmesi durumunda bireyin zorba veya mağdur olduğuna karar verilmektedir. Sosyal Medya Bağımlılığı Ölçeği Kısa Formu: Bu ölçek Van den Eijnden, Lemmens ve Valkenburg (13) tarafından geliştirilmiştir. Ölçeğin geçerlik ve güvenirlik çalışması Taş tarafından yapılmıştır (14). Ölçek, 9 "evet / hayır" sorusundan oluşmaktadır. Beş veya daha fazla madde " evet " olarak kodlanmışsa, bu kişinin sosyal medya bağımlılığı olduğunu gösterir.

\section{Siber Zorbalık ve İnternet Saldırganlığını} Tarama Ölçeği:

Öğrencilerin siber zorbalık ve/veya siber mağduriyet yaşayıp yaşamadıklarını belirlemek için Hinduja ve Patchin (15) tarafından geliştirilen bir ölçek olup, Özdemir ve Akar (16) tarafından Türkçeye adaptasyonu yapılmıștır. Ölçek, 9'ar maddeden oluşan 'Siber Zorba Kurbanı Olma' ve 'Siber Zorba Olma' olmak üzere iki ayrı alt-ölçekten oluşmaktadır. Çalışmamızda SPSS Statistics 20 programı kullanılmıştır. Kategorik değişkenler için frekans ve yüzde kullanılmıştır. Çalışmada kategorik verilerin değerlendirilmesinde "ki kare testi” kullanılmıştır. Anlamlılık düzeyi $\mathrm{p}<0.05$ olarak seçilmiştir.

\section{Bulgular}

Çalışmaya alınan 45 olgunun 35'i $(\% 77,8)$ erkek, 10’u $(\% 22,2)$ kızdır. Olguların 14'ünün $(\% 31,1)$ ebeveynleri ayrı yaşamaktadır. \%17,8'si sigara kullandığını belirtmiş olup, hiçbiri madde kullanmadığını belirtmiştir. İşlendiği iddia olunan en sık suç \%28,9 ile "kavga/yaralama" olup, bunu $\% 15,9$ oranları ile "hırsızlık" ve "cinsel istismar" suçu izlemektedir. Olguların \%40’1 bilgisayarının, \%33,3’ü tabletinin, \%80'i ak1ll telefonunun, \%15,6's1 da oyun konsolunun olduğunu belirtmiştir (Tablo I). \%48,9'u online diğer kişilerle oynanan oyunları, \%22,2'si tek kişilik oyunları tercih ettiğini belirtmiştir.

Akıllı telefon bağımlılığı ölçeğinden elde edilen skorlar “düşük/orta/yüksek" olarak kategorize edildiğinde, \%62,2'sinin düşük, \%24,4'ü orta, \%4.4'ünün yüksek kategorisinde olduğu saptanmıştır. Olguların sadece 2 'sinde $(\% 4,4)$ sosyal medya bağımlılığı saptanmıştır.

Olweus akran zorbalığı ölçeğine göre olgular akran zorbalığ açısından değerlendirildiğinde \%15,6'sının mağdur, \%8,6'sının zorba, \%73,3'ünün katılmayan (ne mağdur ne de zorba) olduğu saptanmıştır. Siber Zorbalık ve İnternet Saldırganlığını Tarama Ölçeğine göre olguların \%15,6'sının siber mağduriyet yaşadığı, \%8,9'unun siber zorbalık yapmış olduğu saptanmıştır.
Tablo I. Çalışma grubunun demografik özellikleri

\begin{tabular}{|c|c|}
\hline Cinsiyet & $\begin{array}{l}\text { Erkek: } 35(\% 77,8) \\
\text { Kız: } 10(\% 22,2)\end{array}$ \\
\hline Sigara kullanımı & $\begin{array}{l}\text { Evet: } 8(\% 17,8) \\
\text { Hayır: } 34(\% 75,6) \\
\text { Bilinmiyor: } 3\end{array}$ \\
\hline Madde kullanımı & $\begin{array}{l}\text { Evet: } 0 \\
\text { Hayır: } 39 \\
\text { Bilinmiyor: } 6\end{array}$ \\
\hline Suç tipi & $\begin{array}{l}\text { Kavga-yaralama: \%28,9 } \\
\text { Hırsızlik: \%15,6 } \\
\text { Cinsel istismar: \%15,6 } \\
\text { Uyuşturucu ticareti: \%2,2 } \\
\text { Diğer: \%26,6 }\end{array}$ \\
\hline Dizüstü bilgisayar & $\begin{array}{l}\text { Var :17 }(\% 17,8) \\
\text { Yok : } 27(\% 60,0)\end{array}$ \\
\hline Masaüstü bilgisayar & $\begin{array}{l}\text { Var: } 18(\% 40) \\
\text { Yok: } 26(\% 57,8)\end{array}$ \\
\hline Tablet & $\begin{array}{l}\text { Var: } 15(\% 33,3) \\
\text { Yok: } 27(\% 60)\end{array}$ \\
\hline Akıllı telefon & $\begin{array}{l}\text { Var:36 (\%80) } \\
\text { Yok:9 }(\% 20)\end{array}$ \\
\hline Oyun konsolu & $\begin{array}{l}\text { Var:7 }(\% 15,6) \\
\text { Yok: } 35(\% 77,8)\end{array}$ \\
\hline
\end{tabular}

Akıllı telefon bağımlılığının akran zorbalığı/mağduriyeti, siber zorba/mağdur olma ile ilişkisi bulunmamıştır. Ölçek değerlendirmeleri Tablo II'de gösterilmiştir.

Tablo II. Ölçek skorlarının değerlendirilmesi

\begin{tabular}{|l|l|}
\hline Ölçek adı & $\mathrm{N}(\%)$ \\
\hline Akıllı Telefon Bağımlılı̆ı & $\begin{array}{l}\text { Düşuk: } 28(\% 62.2) \\
\text { Orta:11 (\%24.4) } \\
\text { Yüksek: } 2(\% 4.4)\end{array}$ \\
\hline Sosyal Medya Bağımlılığı & $\begin{array}{l}\text { Var: } 2(\% 4.4) \\
\text { Yok: } 43(\% 95.6)\end{array}$ \\
\hline Olweus Akran Zorbalı̆ı̆ Ölçeği & $\begin{array}{l}\text { Mağdur: } 7(\% 15.6) \\
\text { Zorba: } 4(\% 8.9) \\
\text { Ne zorba ne de mağdur: 33 (\%73.3) }\end{array}$ \\
\hline $\begin{array}{l}\text { Siber Zorbalık ve İnternet Saldırganlığını } \\
\text { Tarama Ölçeği }\end{array}$ & $\begin{array}{l}\text { Siber-mağduriyet yaşayan: 7 (\%15.6) } \\
\text { Siber-zorbalı yapan: } 4 \text { (\%8.9) }\end{array}$ \\
\hline
\end{tabular}




\section{Tartişma}

Çalışmamızda suça sürüklenen çocuklarda akıllı telefon bağımlılığg, sosyal medya bağımlılığı, siber zorbalık ve siber mağduriyetin değerlendirilmesi amaçlanmıştır. Olguların $\% 28,8$ 'inin orta/yüksek düzeyde akıllı telefon bağımlılığının olduğu, \%15,6'sının siber mağduriyet yaşadığ1, \%8,9'unun siber zorbalık yapmış olduğu saptanmıştır. Sosyal medya bağımlılı̆̆ 1 ise $\% 4,4$ 'ünde tespit edilmiştir.

Akıllı telefonlar, günümüzün en dikkat çekici ve en hızlı yayılma teknolojisidir. 凶Telefon görüşmeleri yapmanın yanı sıra, kullanıcılar oyun oynayabilir, arkadaşlarıyla sohbet edebilir, mesajlaşma sistemlerini kullanabilir, web hizmetlerine (örneğin, bloglar, ana sayfalar, sosyal ağlar) erişebilir ve bilgi arayabilirler $(17,18)$. Akıllı telefonların artan popülaritesi, aşırı kullanım nedeniyle birçok soruna yol açmıştır. Aşırı akıllı telefon kullanımı, okulda veya işte konsantrasyonu engelleyebilir ve boyun sertliği, bulanık görme, bilek veya sırt ağrısı ve uyku bozuklukları gibi fiziksel zorluklara neden olabilir. Ayrıca yüz yüze sosyal etkileşimi ve akademik başarıyı da azaltabilir ve ilişki sorunlarına yol açabilir (17).

Çocuk ve ergenlerin, erişkinlere kıyasla immatür öz kimliklerinden kaynaklanan zayıf kontrol yeteneklerinden dolayı daha güçlü bağımlılık belirtilerine sahip olma olasılıkları daha yüksektir. 『Dahası, çocukların akıllı telefon bağımlılığg eğilimlerinin sorunlu davranışlara yol açtığı ve duygusal zekayı engellediği doğrulandığı için, çocukların akıllı telefonlara olan ilgilerinin akranları ile etkileşim ve fiziksel aktiviteler için fırsatları azaltabileceğine dikkat edilmesi gereklidir (19).

Dünya geneline bakacak olursak Asyalı çocuk ve ergenlerde akıllı telefon bağımlılığının daha fazla olduğu görülmektedir ( Britanya'da \%10, İsviçre'de \%17 ve Kore'de \%31). Ülkemizde ortaokul 5. ve 6 . sinıf öğrencilerinin akıllı telefon bağımlılık düzeylerini değerlendiren bir çalışmada örneklem grubunun \%57,7'sinin akıllı telefon bağımlılığı gösterdiği belirtilmiştir (20). Bizim çalışmamızda suça sürüklenen çocuklarda akıllı telefona sahip olma oran1 \%80 olup, orta/yüksek düzey akıllı telefon bağımlılığı oranı $\% 28,8$ olarak bulunmuştur.

Sosyal medya kullanımı gençlerin hayatlarının normal bir parçası haline gelmiştir. Avantajları arasında arkadaşlarla iletişim kurma, bilgiye hızlı bir şekilde erişme ve yeni bilgiler edinme ve ebeveynler, aile üyeleri ve öğretmenler dahil olmak üzere yetişkin danışmanlarla iletişim halinde olma becerisi bulunur. Fakat aynı zamanda, yoğun ve sorunlu bir sosyal medya kullanımı zararlı niyetlere sahip yabancılarla potansiyel riskli çevrimiçi etkileşimi kolaylaştırır ve bağımlılık davranışlarına, sosyal geri çekilmeye ve bozulmuş sosyal işlevselliğe yol açar. Buna ek olarak, ergenleri siber zorbalık da dahil olmak üzere çevrimiçi saldırganlığa maruz bırakır (21). Farklı teorik çerçeveler ve psikometrik değerlendirmeler nedeniyle, sorunlu sosyal medya kullanımının yaygınlığına ilişkin \%2,8 - \%47 arasında farklı yaygınlık oranları bildirilmiştir (22). Bizim çalışmamızda suça sürüklenen çocuklarda sosyal medya bağımlılığı oranı $\% 4,4$ 'tür. $\mathrm{Bu}$ oranın düşük olmasının muhtemel sebebinin, sosyal medya bağımlığının genel olarak erkeklere nazaran kızlarda daha sık görüldüğü ve bizim çalışmamızda örneklemin \%77,8'ini erkekler oluşturduğu için olduğu düşünülmüştür.

Çocukların, günlük hayatta genelde aile himayesinde olmaları sebebiyle normal hayatta karşılaşmadığı sorunlarla, sanal ortamda karşılaşması ve suçu işleyen kişileri kendine rol model alması olasıdır (23). Bununla uyumlu olarak internet bağımlılığı ve siber zorbalık ilişkisini araştıran çalışmalar, internetin aşırı kullanımı ile siber zorbalık arasında istatistiksel olarak anlamlı pozitif bir ilişki olduğunu ortaya koymuştur $(24,25)$. Üniversite öğrencilerinde akıllı telefon bağımlılığı ile siber zorbalık ilişkisini araştıran bir çalışmada, akıllı telefon bağımlılığının siber zorbalığı öngörebileceği sonucuna varılmıştır (7).

Heiman "siber zorbalığı" elektronik medya yoluyla kasıtlı olarak bir başkasını utandırmak, aşağılamak veya ona zarar vermek olarak tanımlamıştır (26). Failler, kimliklerini gizlemek için takma adlarla kendilerini koruyabilirler. Bu anonimlik, siber zorbalığı İnternet kullanıcıları için daha yaygın ve çekici hale getirir. Zorbaların anonimliği ve dijital içeriğin aktarılmasının kolaylığından dolayı dijital dünya, bireylerin başkalarını istismar etmeleri için muazzam ve bir şekilde sonu gelmez bir platformdur (27).

Belçika'da 1318 ergenle siber zorbalığa katılımlarıyla ilgili yapılan bir çalışmada, özellikle daha önce siber zorbalığa katılmış olma ve çevrimiçi risk davranışlarda bulunmanın siber mağdur olma riskini arttırdığı, aynı zamanda geçmişte siber mağduriyet yaşamanın da siber zorba olma riskini arttırdığı bulunmuştur. Ayrıca kızların siber zorbalık mağduru olma olasılığının daha yüksek, erkeklerin ise elektronik zorbalığa daha meyilli olduğu bulunmuştur (28). 473 öğrenciyle yapılan başka bir çalışmada ise daha önce geleneksel zorbalığa maruz kalan öğrencilerin eski faillerini siber mağdur olarak seçme eğiliminde olduklarını göstermiştir (29). Ülkemizde yapılmış olan bir çalışmada 666 üniversite öğrencisinin \% 22,5'inin en az bir kez siber zorbalık yaptığını ve \% 55,3'ünün hayatları boyunca en az bir kez siber zorbalığa maruz kaldığı bildirildi (30). 372 ilkokul öğrencisiyle yapılan başka bir çalışmada \%27'sinin siber zorbalığın kurbanı, \% 18 'inin zorba ve \% 15'inin hem siber zorba hem de kurban olduğu belirtilmiştir (31). Yine ülkemizde bir grup ergen klinik örneklemde yapılan bir çalışmada siber mağduriyet ve siber zorbalık sıklığ sırasıyla \% 62,6 ve \% 53.3 olarak bildirilmiştir (32). Bizim çalışmamızda adli vaka olarak başvuran suça sürüklenen çocuklarda olguların \%15,6's1 siber mağduriyet yaşadığını, \%8,9'u ise siber zorbalık yapmış olduğunu belirtmiştir. Bizim çalışmamızdaki bu oranların diğer çalışmalara göre daha düşük çıkmasının muhtemel sebebi, bu çocukların kurumumuza adli rapor düzenlenmesi için yönlendirilmiş olmaları ve bu nedenle de işlemiş olabilecekleri başka suçları gizlemiş olmaları olabilir. Ayrıca çalışmamızda akıllı telefon bağımlılığı ile akran zorbalığı/mağduriyeti, siber zorba/mağdur olma arasında anlamlı ilişki bulunamamış olup, bu durum örneklem sayısının az olmasına bağlı olabilir. Bu parametrelerin suç tipleriyle de ilişkisini araştıran daha büyük örneklemi dahil eden çalışmaların literatüre katkı sağlayacağını düşünüyoruz.

Bu çalışma adli vaka olarak kurumumuza başvuran suça 
sürüklenen çocuklarda akıllı telefon bağımlılı̆̆ı, sosyal medya bağımlılığı, siber zorbalık ve siber mağduriyetin değerlendirildiği ilk çalışma olması açısından üstünlük taşımakla birlikte bu çalışmayla ilgili bazı kısıtlılıklar bulunmaktadır. Birincisi örneklem sayısının az olması, siber zorba ve siber mağdur olma gibi alt gruplardaki olgu sayısının az olmasına yol açmış olup, bu durum istatiksel gücü zayıflatmıș olabilir. Ayrıca örneklem sayısının az olması, ölçek alt gruplarıyla işlendiği iddia olunan suç tipi arasında değerlendirme yapmaya olanak sağlamamıştır. İkincisi, ölçek puanlarına katkıda bulunabilecek olan eşlik eden psikiyatrik hastalıklar değerlendirilmemiştir. Üçüncüsü de, zorbalığa ilişkin değerlendirmelerin öz-bildirim ölçekleri ile yapılmış olması, gerçekte varolandan daha düşük zorbalık oranı değerlendirmelerine yol açmış olabilir.

\section{Sonuç:}

Çalışmamızda olguların \%28,8'inin orta/yüksek düzeyde akıllı telefon bağımlılığının olduğu, \%15,6'sının siber mağduriyet yaşadığı, \%8,9'unun siber zorbalık yapmış olduğu saptanmıştır. Adli olgularda akıllı telefon bağımlılığı ve siber zorbalığın değerlendirildiği kontrol grubunu da içeren daha büyük örneklem gruplarında gerçekleştirilecek çalışmalara ihtiyaç vardır. Akıllı telefon bağımlılığının siber zorbalığı öngördüğünü göz önüne alırsak (7), okullarda akıllı telefon bağımlılığı sıklığını tarama ve farkındalığı arttırmaya yönelik çalışmalar siber zorbalığı önlemeye yardımcı olabilir. Çalışmamızın, klinisyenlerin konuyla ilgili farkındalığını artırmak için bir ilk adım olacağını ve gelecekteki çalışmalar için bir başlangıç noktası olacağını umuyoruz. Aynı zamanda hem ailelere yönelik hem de okullarda öğretmen ve öğrencilere yönelik telefon ve bilgisayar gibi teknolojik araçların bilinçli olarak kullanılması, internet güvenliği, siber zorbalık ve siber suç farkındalığını sağlayacak eğitimler verilerek farkındalık, önleme ve müdahale konularında programların hazırlanması ve uygulanması için gerekli adımlar atılmalıdır. Etik Komite Onayı: Çalışma için Akdeniz Üniversitesi Klinik Araştırmalar Etik Kurulu'ndan onay alındı (2019/788). Bu çalışma Helsinki Bildirgesi'ne uygun olarak yapılmıştır. Çalışmaya katılan tüm çocuklara ve ebeveynlerine çalışma hakkında bilgi verilmiştir.

Bilgilendirilmiş Onam: Helsinki Bildirgesi'ne göre, katılımcıların tüm hakları korunmuş ve yazılı bilgilendirilmiş onam alınmıştır

Çıkar Çatışması: Çıkar çatışması bulunmamaktadır.

Finansal Destek: Finansal destek alınmamıştır.

Yazar Katkıları: Konsept -ÖGÇ, AÖ; Tasarım - ÖGÇ, AÖ; Denetim - ÖGÇ,AÖ; Kaynaklar -AÖ, ÖGÇ Materyaller -ÖGÇ,AÖ; Veri Toplanması ve / veya İşlemesi - ÖGÇ,AÖ Analiz ve / veya Yorum - AÖ, ÖGÇ; Literatür Taraması ÖGÇ,AÖ; Yazıyı Yazan - ÖGÇ,AÖ.

\section{Kaynakça}

1. Sarı SA, Çiçek AU, Bütün C, Yıldırım A. Sivas İlinde Suça Sürüklenen Çocuk Olguların Sosyodemografik ve Klinik Özellikleri. The Bulletin of Legal Medicine. 2019;24(3):177-82. https:// doi.org/10.17986/blm.20192450173

2. Köse S, Aslan Z, Başgül ŞS, Şahin S, Yılmaz Ş, Çıtak S, Tezcan E. Bir eğitim ve araştırma hastanesi çocuk psiki yatrisi polikliniğine yönlendirilen adli olgular. Anadolu Psikiyatri Derg. 2011;12:221-5.

3. Kurtuluş A, Salman N, Günbet G, Bora B, Cenger CD, Kemalettin A. Denizli ilinde 12-15 yaş arasındaki suça sürüklenen çocukların sosyodemografik özellikleri. Pamukkale Tıp Dergisi. 2009(1):8-14.

4. Urfalı SO. Sosyal Medya ve Siber zorbalık. http://ww w.umut.org.tr/

5. Choi J, Choi O-j, Kim J-h. Effects of adolescent smart phone addiction on cybersexual delinquency. Soc Behav Pers. 2017;45(5):819-31. https://

doi.org/10.2224/sbp. 5916

6. Ateş EC, Tokay A. Use Of Social Network (Media) and Crime Victimization. Online Journal of Technology Addiction and Cyberbullying. 2018;5(1):1-33.

7. Qudah MFA, Albursan IS, Bakhiet SFA, Hassan EMAH, Alfnan AA, Aljomaa SS, Ateik Al Khadner MM. Smart phone addiction and its relationship with Cyberbullying Among University students. Int J Ment Health Add. 2019;17(3):628-43. https:// doi.org/10.1007/s11469-018-0013-7

8. Kwon M, Lee J-Y, Won W-Y, Park J-W, Min J-A, Hahn C, Gu X, Choi JH, Kim DJ. Development and validation of a smartphone addiction scale (SAS). PloS one. 2013;8(2):e56936. https://doi.org/10.1371/jour nal.pone.0056936

9. Mehmet Ş, Çelik İ, Ertürk Z, Taş UE. Akıllı Telefon Bağımlılığı Ölçeği'nin (ATBÖ) Türk lise öğrencile ri için uyarlama çalışması. Eğitimde ve Psikolojide Ölçme ve Değerlendirme Dergisi. 2016;7(1):156-69. https://doi.org/10.21031/epod.95432

10. Gökbulut B. The Relationship Between Sense Of School Belonging And Smartphone Addiction Of High School Students. International Journal of Education Technology and Scientific Researches .2020;11(5)

11. Olweus D. Revised Olweus bully/victim questionnaire. British Journal of Educational Psychology. 1996.

12. Sipahi HT, Karababa AO. Olweus öğrenciler için akran zorbalığı anketinin Türkçeye ve Türkiye'ye uyarlanması ve geçerlilik, güvenirlik analizi. Ege Tıp Dergisi. 2018;57(4):222-7.

13. Van Den Eijnden RJ, Lemmens JS, Valkenburg PM. The social media disorder scale. Comput Hum Behav. 2016;61:478-87. https:// doi.org/10.1016/j.chb.2016.03.038

14. Taş İ. The Social Media Addiction Scale (SF) for Adoles cents: A Study of Validity and Reliability. Online Journal of Technology Addiction and Cyberbullying. 2017;4(1):27-40. 
15. Hinduja S, Patchin JW. Cyberbullying: An exploratory analysis of factors related to offending and victimization. Dev behav. 2008; 29(2):129-56. https:// doi.org/10.1080/01639620701457816

16. Özdemir M, Akar F. Lise öğrencilerinin siber-zorbalığa ilişkin görüşlerinin bazı değişkenler bakımından incelen mesi. Kuram ve Uygulamada Egitim Yönetimi Dergisi. 2011;17(4):605-26.

17. Choi S-W, Kim D-J, Choi J-S, Ahn H, Choi E-J, Song W-Y, Kim S, Youn H. Comparison of risk and protective factors associated with smartphone addiction and Internet addiction. $\mathrm{J}$ behav addict. 2015;4(4):308-14 . https://doi.org/10.1556/2006.4.2015.043

18. Wang P, Zhao M, Wang X, Xie X, Wang Y, Lei L. Peer relationship and adolescent smartphone addiction: The mediating role of self-esteem and the moderating role of the need to belong. J behav addic. 2017;6(4):708-17. https://doi.org/10.1556/2006.6.2017.079

19. Cho K-S, Lee J-M. Influence of smartphone addiction proneness of young children on problematic behaviors and emotional intelligence: Mediating self-assessment effects of parents using smartphones. Comput Hum Behav. 2017; 66:303-11. https:// doi.org/10.1016/j.chb.2016.09.063

20. Yıldız Durak H, Seferoğlu S. Ortaokul öğrencilerinin akıllı telefon kullanımları ve bağımlılık düzeyleriyle ilgili unsurlar. Eğitim Teknolojisi Kuram ve Uygulama 2018,1(8). https://doi.org/10.17943/etku.288822

21. Craig W, Boniel-Nissim M, King N, Walsh SD, Boer M, Donnelly PD, Fisch YH, Cieslik MM, Matos MG, Cosma A, Eijnden R, Vieno A, Elgar F, Molcho M, Bjereld Y, Pickett W. Social media use and cyber-bully ing: a cross-national analysis of young people in 42 countries. J Adolesc Health. 2020;66(6):S100-S8. https://doi.org/10.1016/j.jadohealth.2020.03.006

22. Bányai F, Zsila Á, Király O, Maraz A, Elekes Z, Griffiths MD, Demetrovicz Z. Problematic social media use: Results from a large-scale nationally representative adolescent sample. PLoS One. 2017;12(1):e0169839. https://doi.org/10.1371/journal.pone.0169839

23. Ateş EC, Saluk A. Bilişiım Suçları Kapsamında Suça Sürüklenen Çocukların İncelenmesi. Humanitas Uluslar aras1 Sosyal bilimler Dergisi. 2018.

https://doi.org/10.20304/humanitas.425792
24. Chang F-C, Chiu C-H, Miao N-F, Chen P-H, Lee C-M, Chiang J-T, Pan YC. The relationship between parental mediation and Internet addiction among adolescents, and the association with cyberbullying and depression. Compr psychiatry. 2015;57:21-8. https:// doi.org/10.1016/j.comppsych.2014.11.013

25. Nartgün ŞS, Cicioğlu M. Problematic Internet Use and Cyber Bullying in Vocational School Students. Interna tional online journal of educational sciences. 2015;7(3).

26. Heiman T, Olenik-Shemesh D, Eden S. Cyberbullying involvement among students with ADHD: Relation to loneliness, self-efficacy and social support. Eur J Spec Needs Educ. 2015;30(1):15-29. https:// doi.org/10.1080/08856257.2014.943562

27. Akbulut Y, Eristi B. Cyberbullying and victimisation among Turkish university students. Australas. J. Educ. Technol.. 2011;27(7). https://doi.org/10.14742/ajet.910

28. Walrave M, Heirman W. Cyberbullying: Predicting victimisation and perpetration. Child Soc. 2011;25(1):59-72. https://doi.org/10.1111/j.1099-0860.2009.00260.x

29. Konig A, Gollwitzer M, Steffgen G. Cyberbullying as an act of revenge? AUST J GUID COUNS. 2010;20(2):210. https://doi.org/10.1375/ajgc.20.2.210

30. Dilmac B. Psychological needs as a predictor of cyber bullying: A preliminary report on college students. Educational Sciences: Theory and Practice. 2009;9(3):1307-25.

31. Arslan S, Savaser S, Hallett V, Balci S. Cyberbullying among primary school students in Turkey: Self-reported prevalence and associations with home and school life. Cyberpsychol Behav Soc Netw. 2012;15(10):527-33. https://doi.org/10.1089/cyber.2012.0207

32. Gül H, Fırat S, Sertçelik M, Gül A, Gürel Y, Kıııç BG. Cyberbullying among a clinical adolescent sample in Turkey: effects of problematic smartphone use, psychiat ric symptoms, and emotion regulation difficulties. Psychiatry and Clinical Psychopharmacology. 2019;29(4):547-57. https:// doi.org/10.1080/24750573.2018.1472923 